\title{
Involvement of the Cingulate Cortex in Anosognosia: A Multimodal Neuroimaging Study in Alzheimer's Disease Patients
}

\author{
Laura Guerrier ${ }^{\mathrm{a}, *}$, Johanne Le Men ${ }^{\mathrm{b}}$, Anaïs Gane ${ }^{\mathrm{e}}$, Mélanie Planton ${ }^{\mathrm{a}, \mathrm{b}}$, Anne-Sophie Salabert ${ }^{\mathrm{a}, \mathrm{d}}$, \\ Pierre Payoux $^{\mathrm{a}, \mathrm{d}}$, Hervé Dumas ${ }^{\mathrm{c}, \dagger}$, Fabrice Bonneville ${ }^{\mathrm{a}, \mathrm{c}}$, Patrice Péran ${ }^{\mathrm{a}, 1}$ and Jérémie Pariente ${ }^{\mathrm{a}, \mathrm{b}, 1}$ \\ ${ }^{a}$ ToNIC, Toulouse NeuroImaging Center, University of Toulouse, Inserm, UPS, France \\ ${ }^{\mathrm{b}}$ Department of Neurology, University Hospital of Toulouse, Toulouse, France \\ ${ }^{\mathrm{c}}$ Department of Neuroradiology, University Hospital of Toulouse, Toulouse, France \\ ${ }^{\mathrm{d}}$ Department of Nuclear Medicine, University Hospital of Toulouse, Toulouse, France \\ ${ }^{\mathrm{e}}$ UMRIO27 INSERM, University of Toulouse III, Toulouse University Hospital (CHU), Toulouse, France
}

Accepted 26 June 2018

\begin{abstract}
.
Background: Anosognosia is a frequent symptom of Alzheimer's disease (AD), but its neural substrates remain in question. Objective: In this study, we combined neuroimaging with a neuropsychological evaluation to assess neural substrates of anosognosia.

Methods: We prospectively recruited 30 patients with probable early-stage AD and matched healthy controls. Participants underwent MRI, FDG-PET, and a neuropsychological evaluation that includes an assessment of anosognosia. In the AD group, correlations between the anosognosia score, neuroimaging modalities, and neuropsychological performance were performed.

Results: Atrophy and hypometabolism were correlated with the anosognosia score in the left dorsal anterior cingulate cortex. The anosognosia score was also correlated with atrophy of the cerebellar vermis, the left postcentral gyrus, and the right fusiform gyrus. No relation was found between anosognosia and the neuropsychological assessment.

Discussion: Structural and metabolic alteration in the dorsal anterior cingulate cortex seems to be associated with a diminution of awareness in patients with early-stage AD.

Keywords: Alzheimer's disease, anosognosia, FDG-positron emission tomography, magnetic resonance imaging, neuropsychological assessment
\end{abstract}

\section{INTRODUCTION}

For several years, lack of awareness of cognitive deficits has been reported in dementia with high prevalence [1, 2], in psychiatric disorders [3] or

\footnotetext{
${ }^{1}$ These authors contributed equally to this work.

${ }^{\dagger}$ Deceased.

*Correspondence to: Laura Guerrier, UMR 1214 - ToNIC INSERM, Pavillon Baudot CHU Purpan, 31024 Toulouse Cedex 3 , France. Tel.: +33 5627461 92; E-mail: laura.guerrier@inserm.fr.
}

following stroke [4]. Although some regions are commonly impacted in relation to the lack of awareness, it would seem that this phenomenon is pathologydependent. In Alzheimer's disease (AD), while a recent meta-analysis [5] reported no difference in awareness level between healthy subjects and mild cognitive impairment (MCI) patients, others authors reported a lack of awareness from MCI (e.g., $[6,7])$ to dementia stages (e.g., [8]). According to the literature, this phenomenon is not systematically observed 
in the course of the disease or among patients [6, 9]. Different terminologies such as "unawareness", "lack of insight", "anosognosia", or "denial" have been used to refer to this phenomenon. In this study, we propose to use the term "anosognosia" to refer to the "impaired ability to recognize the presence or appreciate the severity of cognitive deficits" [10].

The use of different evaluation methods combined with a lack of consensus on the meaning of the term "anosognosia" [9] can explain the variability of the prevalence of anosognosia, from $23 \%$ to $75 \%$ across studies [9]. Therefore, synthesizing neuropsychological and neuroimaging findings remains difficult [11].

Cognitive mechanisms of anosognosia remain uncertain, but descriptive models have been proposed. From the metacognitive model of Nelson and Narens [12], Agnew and Morris [13] described three types of anosognosia in AD patients: 1) Mnemonic anosognosia refers to a deficit in the consolidation of new information in the personal data base; 2) Executive anosognosia refers to an alteration of the comparator mechanism allowing the comparison between the actual performance and the stored past information; and 3) Primary anosognosia refers to a direct deficit within the metacognitive awareness system, usually involved in bringing information to consciousness. However, while some authors [5] described a positive correlation between anosognosia and neurocognitive abilities in MCI patients (i.e., the more anosognosic the patient, the more severe the cognitive impairment), other reported a specific alteration of executive functions, in agreement with executive anosognosia $[8,14,15]$ or a specific alteration in memory performance in anosognosic AD patients [10, 16]. In 2013, Morris and Mograbi [17] revised this model by integrating the role of emotional processes. Positive correlation between anosognosia and apathy have already been reported in the literature in $\mathrm{AD}$ patients [18] (i.e., the more anosognosic the patient, the more apathetic they are) and could play an important role in awareness processes. Therefore, the pattern of cognitive impairment may not predict anosognosia symptoms or its severity. In this context, neuroimaging investigations could contribute to this understanding.

Magnetic resonance imaging (MRI) studies have reported a correlation between anosognosia severity and the atrophy of various cortical regions: the ventromedial prefrontal cortex [19], left superior frontal gyrus [20], anterior cingulate [21], right pars triangularis of the inferior frontal cortex [21], and the cerebellar vermis [21]. PET studies have shown hypometabolism in the orbitofrontal cortex [22-24], cingulate cortex [22, 23], medial temporal regions [24], and the temporoparietal cortex [24]. In a recent study combining fluorodeoxyglucose-positron emission tomography (FDG-PET) and resting state fMRI imaging in $23 \mathrm{AD}$ patients, Perrotin and colleagues [22] reported that anosognosia could be due to an alteration of a specific brain area involved in self (posterior cingulate cortex) and executive functions (orbitofrontal cortex), as well as a disconnection within and between these regions and the temporal lobe, leading to impaired integration of new information in the personal data base. The neuronal substrate of anosognosia remains debatable and thus requires further studies.

The objective of the present study was to explore the neural basis of anosognosia in AD patients. An evaluation of executive and memory functions was carried out, as well as multimodal imaging using brain MRI and FDG-PET.

\section{METHODS}

This study was approved by the local Ethics Committee (Comité d'Ethique de la Recherche No. 57-1112), and all participants gave their informed consent. Thirty patients with probable early-stage $\mathrm{AD}$ were included in the present study. They were recruited through the outpatient Memory Clinic of the Neurology Department of Toulouse University Hospital (France). The clinical diagnosis of probable AD was made in accordance with IWG-2 criteria for typical AD [25]. Patients were included if they met the following criteria: age $\geq 50$ years; no probable depression (Cornell Scale <14/48, [26]); impairment of anterograde verbal memory assessed by the Free and Cued Selective Reminding Test (FCSRT, sum of three free recalls $\leq 17 / 48$ and/or sum of free and cued recalls $\leq 40 / 48$ [27]); evidence of amyloid pathology in the cerebrospinal fluid (phospho-Tau $\geq 60 \mathrm{pg} / \mathrm{mL}$ and Innotest Amyloid Tau Index $\leq 0.8$; or $\mathrm{A} \beta_{42} / \mathrm{A} \beta_{40}$ $<0.045$ [28]); and/or positive florbetapir PET imaging [25].

Thirty-five healthy controls (HC) matched for age, sex, and education were included in this study. Among them, 19 were used as a reference group for neuropsychological data and 16 were used as a reference group for neuroimaging data. They had no history or clinical evidence of psychological or neurological disorders, were cognitively intact (MiniMental State Examination (MMSE) >24/30) and had no cognitive complaint. 


\section{Anosognosia assessment}

The severity of anosognosia was evaluated with the French version [29] of the Cognitive Difficulties Scale (CDS, [30]). This 39-item questionnaire was modified to exclude the 4 gender-dependent items and was completed by AD patients and their respective caregivers to assess 3 domains of cognitive difficulties in everyday life: attention/concentration, memory, and orientation. For each item, such as "I forget which day of the week it is" or "I have some difficulty staying focused on a job or occupation," participants evaluated the frequency of cognitive difficulties on a 5-point scale (from $0=$ "never" to 4 = "always"). The anosognosia score was calculated as follows: (sum of scores of the 35 items completed by the caregiver) - (sum of scores of the 35 items completed by the participant). Thus, the greater the score, the less aware the participant was of his difficulties. In order to better appreciate this phenomenon of anosognosia in $\mathrm{AD}$ patients, healthy controls and their respective relative also completed this questionnaire, and the calculation of the anosognosia score was the same as for the patients.

\section{Neuropsychological assessment}

Ten neuropsychological tests covering 5 cognitive domains were selected to comprehensively assess the cognitive processes often altered in patients with AD. Memory functions were evaluated with the Rivermead Behavioral Memory Test III [31] to assess visual, verbal, prospective, spatial memories, and the ability to learn a new task. Executive processes were explored with the Trail Making Test (TMT) [32] for flexibility, the Stroop test [32] for inhibition, phonemic and semantic verbal fluency [32] for initiation, and the Digit Span Forward and Backward test (WAIS-III) [33] for verbal working memory. We used the raw response times (s) for the TMT part A and Stroop naming and reading to assess the speed of information processing. A picture-naming test was chosen for language [34], and Mahieux's test for ideational and ideomotor apraxia [35]. Finally, apathy was measured with the Apathy Inventory [36], depression with the Cornell Scale [26], and autonomy with the Activities of Daily Living Questionnaire [37] and the Lawton Instrumental Activities of Daily Living Scale [38]. The two latter selfcare questionnaires were completed by caregivers only.

\section{Brain imaging}

\section{Data acquisition}

MRI and FDG-PET imaging were performed for $16 \mathrm{HC}$ and $30 \mathrm{AD}$ patients.

A high resolution anatomical image, using a 3D T1-weighted sequence (in plane resolution $1 \times 1 \mathrm{~mm}$, slice thickness $1 \mathrm{~mm}$ ) and a T2-weighted sequence (reconstructed resolution $0.45 \times 0.45 \times 3 \mathrm{~mm}^{3}$ ) were obtained. FDG-PET scans were performed on a PET/computed tomography (CT) scanner (3D detection mode, producing images with $1 \times 1 \times 1.5 \mathrm{~mm}$ voxels). Cerebral emission scans began 20 min after the injection of $1.85 \mathrm{MBq} / \mathrm{kg}$ weight of FDG on average and lasted for $10 \mathrm{~min}$. Both CT and PET scans were acquired.

\section{Data processing and analyses}

Grey matter density was assessed using a voxelbased morphometry method on Statistical Parametric Mapping version 12 (SPM 12, Wellcome Trust Centre for Neuroimaging) software running on MATLAB (MathWorks, Inc.). For each subject, the 3D T1 sequence was segmented to isolate grey matter and white matter partitions, modulated for deformation, normalized to the MNI space (Montreal Neurological Institute), and smoothed $(8 \times 8 \times 8 \mathrm{~mm})$. Three MRI scans from the AD group were excluded from imaging processing due to poor image quality.

FDG-PET scans were whole-brain normalized using a PET template from SPM12 software and smoothed $(8 \times 8 \times 8 \mathrm{~mm})$. Two FDG-PET scans from the patient group were excluded from imaging processing due to poor image quality.

\section{Statistical analysis}

Normality of clinical and neuropsychological data distribution was tested using the Shapiro-Wilk test. Intergroup comparison of the anosognosia score was performed using Student's $t$-test for independent sample. Intergroup comparison of the neuropsychological assessment was performed using the Mann-Whitney test. A threshold of $p<0.05$ was used.

The relationship between the anosognosia score and neuropsychological performance in $\mathrm{AD}$ patients was evaluated using the Spearman correlation and corrected for multiple correlations using Bonferroni's procedure. Inter-group comparisons using voxelbased analysis (voxel level $p<0.05$, FWE-corrected) were performed for MRI and FDG-PET imaging. In the $\mathrm{AD}$ group, a voxel-wise correlation analysis 
was also performed between the anosognosia score and grey matter density, and between the anosognosia score and metabolism (voxel level $p<0.001$, cluster $>70$ voxels). Correlations between imaging modalities (MRI and FDG-PET scans) and cognitive functions ((FCSRT (Sum of free \& cued recalls, 148)) and phonologic fluencies) have been computed in order to verify that altered regions are specific to the phenomenon of anosognosia.

To evaluate the potential mediating effect of apathy on anosognosia, correlations were also conducted between the apathy score and grey matter density and between the apathy score and metabolism (voxel level $p<0.001$, cluster $>70$ voxels).

In the case where an alteration on the same region was found in both imaging modality, and thus to validate the relationship between grey density and metabolism, a Pearson correlation was used between the MRI and the FDG-PET data after extraction with the MARSBAR software running on MATLAB [39]. To confirm the spatial coherence between the two modalities, we conducted a Pearson correlation between the anosognosia score and the MRI data extracted from the FDG-PET cluster and between the anosognosia score and the FDG-PET data extracted from the MRI cluster.

\section{RESULTS}

No difference in age and education was found between the $\mathrm{AD}$ and the $\mathrm{HC}$ group for the neuropsychological assessment (Age (AD: 70.5 [8.75], HC $(n=19)$ : 65 [20], $p=0.38)$; level of education in years (AD: 12 [3.5], HC: 12 [4], $p=0.84$ ) and between the $\mathrm{AD}$ group and the $\mathrm{HC}$ on imaging assessment (Age (AD: 70.5 [8.75], HC $(n=16): 67.5$ [6.25], $p=0.44)$ and level of education in years (AD: 12 [3.5], HC: 13.5 [6.5], $p=0.16$ ). The anosognosia score was not related to the age and level of education in $\mathrm{AD}$ patients (see Supplementary Table 1).

\section{Anosognosia and neuropsychological scores}

Neuropsychological scores were lower in AD patients compared to healthy controls for memory, executive functioning, speed processing, praxis, and language. Concerning the behavioral assessment, there was no depression in the $\mathrm{HC}$ and $\mathrm{AD}$ groups and the scores were similar among the groups. However, AD patients were more apathetic than healthy controls. The anosognosia score was higher in AD patients than in healthy controls (Table 1, Fig. 1).
No correlation was found between the anosognosia score and any of the neuropsychological performances in the AD group (see Supplementary Table 1), either for memory or executive function.

\section{Brain imaging and anosognosia}

A difference in the density of grey matter in both left and right hippocampi and precuneus was found in $\mathrm{AD}$ patients in comparison to healthy controls (see Supplementary Figure 1A). We also found hypometabolism in both the left and right precuneus and parietal lobe in $\mathrm{AD}$ patients in comparison to healthy controls (see Supplementary Figure 1B).

Negative correlations were observed between the anosognosia score and the density of grey matter in the left dorsal anterior cingulate cortex (dACC), left cerebellar vermis, left postcentral gyrus, and in the right fusiform gyrus (see Supplementary Figure 2). Concerning the PET imaging, a negative correlation was found between the anosognosia score and metabolism in the identical region, the left dACC. Details on the topographical location of these correlations and $T$ scores are given in Table 2. Thus, the more anosognosic the patient, the more reduced the grey matter density and metabolism in the left dorsal anterior cingulate cortex (Fig. 2). Metabolism and grey matter density were positively correlated in this region $(r=0.41, p=0.036)$. To confirm that is the same region involved in the two modalities, we also found a negative correlation between the anosognosia score and the MRI data extracted from the FDG-PET cluster $(r=-0.55 ; p=0.003)$ and the anosognosia score and FDG-PET data extracted from the MRI cluster of the left dACC $(r=-0.6$; $p=0.001$ ).

Cognitive functions ((FCSRT (Sum of free \& cued recalls, /48)) and phonologic fluency) were significantly correlated with grey matter density (see Table 3). No correlation was found between these cognitive functions and metabolism.

Apathy score and grey matter density were negatively correlated in the left associative visual cortex (x, y, z: $-44,-77,-2 ; \mathrm{k}=177 ; \mathrm{T}=4.8$ ). Regarding results between the apathy score and metabolism, negative correlations were found in the right fusiform gyrus (x, y, z: 40, $-38,-14 ; \mathrm{k}=245 ; \mathrm{T}=5.03)$, the left associative visual cortex ( $\mathrm{x}, \mathrm{y}, \mathrm{z}:-42,-74,4 ; \mathrm{k}=366$; $\mathrm{T}=4.49)$, and in the right ( $\mathrm{x}, \mathrm{y}, \mathrm{z}: 42,-32,18 ; \mathrm{k}=249$; $\mathrm{T} 4.48$ ) and left parietal operculum (x, y, z: $-34,-28$, $18 ; \mathrm{k}=127 ; \mathrm{T}=4.05)$. 
Table 1

Demographic data and neuropsychological performance of $\mathrm{HC}$ and $\mathrm{AD}$ patients

\begin{tabular}{|c|c|c|c|}
\hline & $\mathrm{HC}(n=19)$ & $\mathrm{AD}(n=30)$ & $p$ \\
\hline \multicolumn{4}{|l|}{ Anosognosia assessment } \\
\hline CDS Participant & $36[22]$ & $42[17.5]$ & 0.04 \\
\hline CDS Caregiver & $27.1[16.8]$ & $56.5[20.9]$ & $<0.001$ \\
\hline Anosognosia score & $-8.8[20.7]$ & $9[26.5]$ & 0.015 \\
\hline \multicolumn{4}{|l|}{ Cognitive level } \\
\hline $\operatorname{MMSE}(/ 30)$ & $29[2]$ & $24[3.8]$ & $<0.001$ \\
\hline \multicolumn{4}{|l|}{ Memory functions } \\
\hline \multicolumn{4}{|l|}{ Visual memory } \\
\hline RBMT III (Total corrected answers, /30) & $28[1.5]$ & $19[9.8]$ & $<0.001$ \\
\hline \multicolumn{4}{|l|}{ Verbal memory } \\
\hline RBMT III (Total corrected answers, /50) & $27[3.25]$ & $5.75[3.9]$ & $<0.001$ \\
\hline FCSRT (Sum of free recalls, /48) & $35[4]$ & $7.5[6.75]$ & $<0.001$ \\
\hline FCSRT (Sum of free \& cued recalls, /48) & $47[1]$ & $26.5[14]$ & $<0.001$ \\
\hline \multicolumn{4}{|l|}{ Spatial memory } \\
\hline RBMT III (Total corrected answers, /26) & $26[3]$ & $9[12.5]$ & $<0.001$ \\
\hline \multicolumn{4}{|l|}{ Prospective memory } \\
\hline RBMT III (Total corrected answers, /12) & $12[1]$ & $4[6.75]$ & $<0.001$ \\
\hline \multicolumn{4}{|l|}{ Ability to learn a new task } \\
\hline RBMT III (Total corrected answers, /68) & $59[16]$ & 20 [17.5] & $<0.001$ \\
\hline \multicolumn{4}{|l|}{ Executive functions } \\
\hline \multicolumn{4}{|l|}{ Flexibility } \\
\hline TMT B-A, time & $40[29.5]$ & $148[151]$ & $<0.001$ \\
\hline \multicolumn{4}{|l|}{ Inhibition } \\
\hline Stroop test, interference score (IS), time & $56[49.8]$ & $102[84]$ & 0.001 \\
\hline \multicolumn{4}{|l|}{ Initiation } \\
\hline Phonologic fluency (P) & $21[10]$ & $19.5[8.8]$ & NS \\
\hline Semantic fluency (Animals) & $34[10]$ & $20[4.8]$ & $<0.001$ \\
\hline \multicolumn{4}{|l|}{ Verbal working memory } \\
\hline Digit span, forward (/16) & $8[2]$ & $7[1.8]$ & NS \\
\hline Digit span, backward (/16) & $6[1]$ & $5[2]$ & $<0.001$ \\
\hline \multicolumn{4}{|l|}{ Processing speed } \\
\hline Stroop denomination, time & $67[16.8]$ & $83.5[28.8]$ & 0.001 \\
\hline Stroop reading, time & $48[9.3]$ & $49.5[13]$ & NS \\
\hline TMT A, time & $33[17]$ & $55.5[35.5]$ & 0.001 \\
\hline \multicolumn{4}{|l|}{ Language } \\
\hline Naming (/36) & $35[1]$ & $31[4]$ & $<0.001$ \\
\hline \multicolumn{4}{|l|}{ Praxis } \\
\hline Gestural praxis (/23) & $23[1]$ & $22[2]$ & 0.009 \\
\hline \multicolumn{4}{|l|}{ Behavioral assessment } \\
\hline Depression Scale (/38) & $2[3.5]$ & $2[3]$ & NS \\
\hline Apathy (/36) & $0[0]$ & $1[3.8]$ & 0.001 \\
\hline \multicolumn{4}{|l|}{ Autonomy } \\
\hline $\operatorname{ADL}(/ 6)$ & $6[0]$ & $6[0]$ & NS \\
\hline $\operatorname{IADL}(/ 8)$ & $8[0]$ & $7[2.8]$ & $<0.001$ \\
\hline
\end{tabular}

HC, healthy controls; AD, Alzheimer's disease; CDS, Cognitive Difficulties Scale; MMSE, MiniMental State Examination; RBMT III, Rivermead Behavioral Memory Test III; FCSRT, Free and Cued Selective Reminding Test; TMT, Trail Making Test; ADL, Activities of Daily Living Questionnaire; IADL, The Lawton Instrumental Activities of Daily Living Scale. Values shown are median [InterQuartile Range] for the not normally distributed data and mean [Standard Deviation] for normally distributed data.

\section{DISCUSSION}

The main aim of this study was to explore neural substrates of anosognosia in AD patients. In accordance with previous studies [22, 40], AD patients exhibited more anosognosia than healthy controls. We demonstrated a correlation between anosognosia and atrophy in the dorsal anterior cingulate cortex (dACC). This result is reinforced by the independent analysis of PET-FDG images, in which we found a correlation between anosognosia and hypometabolism in the very same region of the anterior cingulate cortex. Co-localization between MRI and PET findings seems to be a good indicator for 


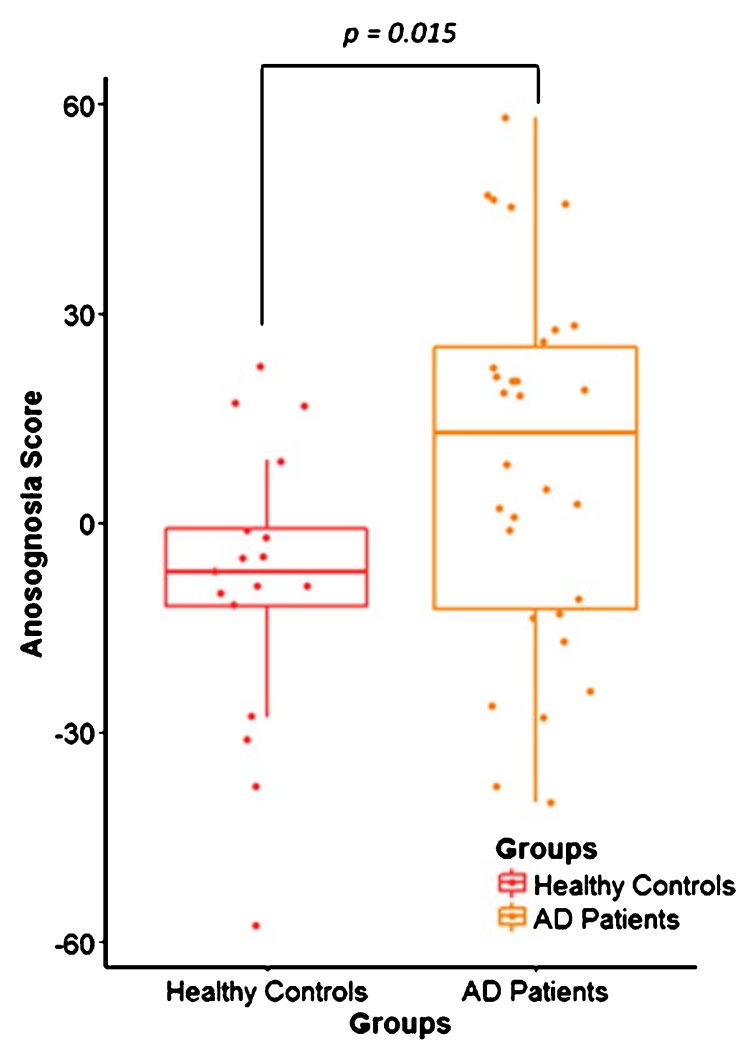

Fig. 1. Distribution of the anosognosia score in healthy controls (HC) and Alzheimer's disease (AD) patients. Box plot shows the difference between the anosognosia score distribution in the HC group $(n=17)$ in red and $\mathrm{AD}$ patients $(n=30)$ in yellow, with $p=0.015$.

the pertinence of the results [41]. It is important to note that we did not find any correlation between apathy and grey matter density or metabolism in the dACC. Concerning the neuropsychological assessment, no correlation was found between anosognosia and cognitive performance in the AD group. Correlations with cognitive functions ((FCSRT (Sum of free \& cued recalls, /48)) and phonologic fluency) confirm that: 1) there is a coherent link between the cognitive alterations found in our patients and their imaging pattern and 2) there are specific alterations of the dorsal anterior cingulate cortex, posterior vermis, postcentral, and fusiform related to the phenomenon of anosognosia.

The part of the cingulate positively correlated with anosognosia scores in our study belongs to the dACC [42], but the terminology varies in the literature. Other authors have named it the supragenual anterior cingulate cortex (SACC) [43], or the posterior middle cingulate cortex [44]. The dACC is involved in highlevel executive functions, such as response selection, error detection, performance monitoring, reappraisal and judgement of self-related stimuli $[43,45,46]$.

Impairment of the dACC has already been reported in other imaging studies. Wong et al., in 2016 [47], reported grey matter atrophy of the bilateral anterior cingulate and paracingulate cortices in 16 $\mathrm{AD}$ and 22 frontotemporal dementia patients using the self-reference effect paradigm. Specific alterations of the right posterior cingulate cortex and orbital frontal cortex have also been found in $\mathrm{AD}$ patients whereas a specific alteration of the right medial prefrontal and subcallosal cortices was found in frontotemporal dementia patients. In a SPECT study, decreased perfusion in the dACC and inferior, medial, and orbital frontal lobes was found in $\mathrm{AD}$ patients with a high score of anosognosia in comparison to a group of $\mathrm{AD}$ patients without anosognosia [23]. These authors explained that anosognosia may be associated with an alteration of these regions involved in error awareness. In a functional MRI study, Amanzio et al. [48] reported decreased activity in the $\mathrm{AACC}$ and rostral prefrontal cortex during a Go/no-Go task in anosognosic AD patients, whereas these regions are usually activated to make a choice between two situations. They also found a diminution of activation of the right postcentral gyrus and parietotemporal-occipital junction, as well as the striatum and cerebellum during the same tasks. They supposed that a reduced functional recruitment of these cingulofrontal and parietotemporal regions could be associated with anosognosia in these patients.

An explanation for anosognosia in $\mathrm{AD}$ is the "petrified-self" model [49]. According to this model, the inability of the patient to update their own personal database leads patients to refer to their premorbid personal information. This is coherent with Conway's "Self-Memory System" model [50], in which self and autobiographical memory are interdependent [51]. One hypothesis concerning the lack of integration of this self-information could be an alteration of executive processes involved in the selection, comparison, and updating mechanisms. We may hypothesize that dACC is important in this updating process, and therefore a structural and functional impairment of this region may have an effect on awareness processes. Ansell and Bucks in (2006) [52] were interested in this mechanism and measured AD patients' pre- and post-estimation after learning word lists. They reported that AD patients were capable of adjusting their estimation after many repetitions, but accuracy was lower than healthy controls' 
Table 2

Brain areas correlated with the anosognosia score on MRI and FDG-PET imaging

\begin{tabular}{lccccl}
\hline Scans & $\begin{array}{c}\text { MNI } \\
\text { coordinates } \\
(\mathrm{x} ; \mathrm{y} ; \mathrm{z})\end{array}$ & $\begin{array}{c}\text { Number } \\
\text { of voxels }\end{array}$ & $\mathrm{T}$ & $\begin{array}{c}\text { Correlation } \\
\text { coefficient } \\
(p \text {-value })\end{array}$ & Anatomical structures \\
\hline MRI & $-11 ;-2 ; 42$ & 75 & 4.25 & $-0.61(p<0.001)$ & Left dorsal anterior cingulate cortex (BA 24) \\
& $0 ;-68 ;-27$ & 162 & 4.07 & $-0.62(p<0.001)$ & Cerebellum, Posterior vermis \\
& $-53 ;-2 ; 39$ & 98 & 4.01 & $-0.63(p<0.001)$ & Left postcentral gyrus (BA 6) \\
FDG-PET & $33 ; 0 ;-36$ & 92 & 3.99 & $-0.61(p<0.001)$ & Right fusiform gyrus (BA 20) \\
\hline
\end{tabular}

Correlation coefficient and $p$-values were calculated after extraction of data with MARSBAR.
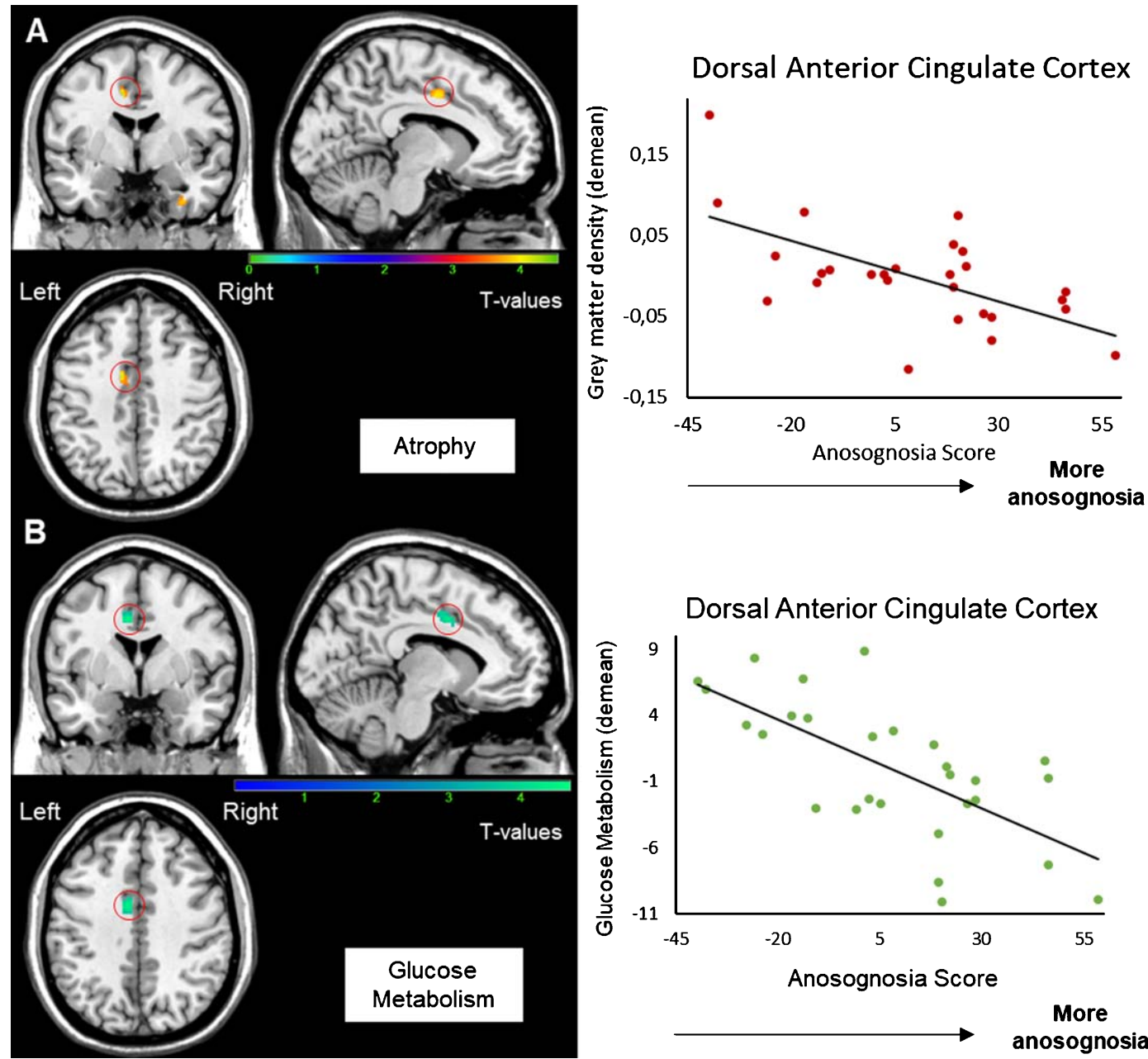

\section{Dorsal Anterior Cingulate Cortex}

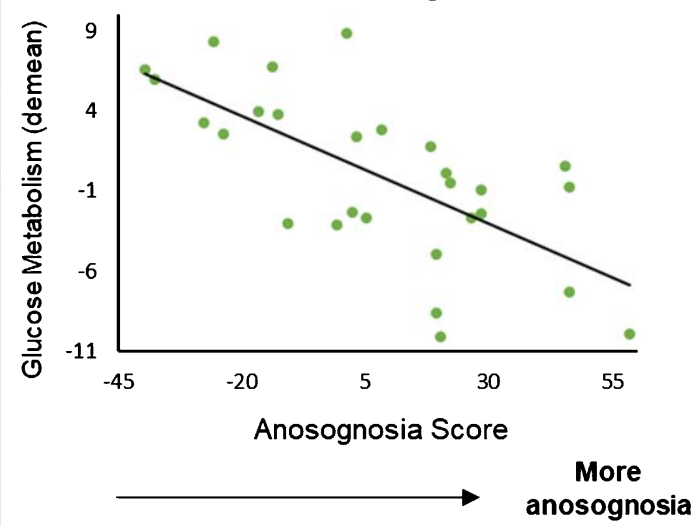

Fig. 2. Correlation between the anosognosia score and MRI (A) and FDG-PET scans (B). Results were obtained from 27 T1-3D scans (A) and 28 FDG-PET scans (B) in Alzheimer's disease patients. The statistical threshold is puncorr $<0.001$ ( $\mathrm{k}>70$ voxels). Correlations are performed on the whole cluster after extraction of data with MARSBAR.

estimations, suggesting that the comparator mechanism was impaired in AD patients, in agreement with executive anosognosia.

Executive dysfunction in $\mathrm{AD}$ patients with anosognosia, supporting the executive anosognosia hypothesis, is frequently reported [8, 11, 15, 48] but was not observed in our study. We acknowledge that our clinical executive tests had a low specificity for assessing response selection, error detection, and performance monitoring. A more specific executive 
Table 3

Brain areas correlated with cognitive functions on MRI imaging

\begin{tabular}{lcccl}
\hline $\begin{array}{l}\text { Neuropsychological } \\
\text { assessment }\end{array}$ & $\begin{array}{c}\text { MNI } \\
\text { coordinates } \\
\text { (x; y; z) }\end{array}$ & $\begin{array}{c}\text { Number of } \\
\text { voxels }\end{array}$ & $\mathrm{T}$ & Anatomical structures \\
\hline FCSRT (Sum of free \& cued & $27 ;-38 ;-3$ & 328 & 5.04 & Right hippocampus \\
recalls, /48) & $-23 ;-39 ; 0$ & 139 & 4.13 & Left hippocampus \\
& $18 ;-47 ;-12$ & 180 & 4.05 & Right visual cortex associative \\
Phonologic fluency (letter P) & $-24 ; 51 ; 27$ & 1574 & 5.74 & Left anterior prefrontal cortex \\
& $60 ;-50 ; 30$ & 293 & 5.44 & Right gyrus angular \\
& $-51 ;-36 ; 20$ & 359 & 4.16 & Left gyrus supramarginal \\
& $50 ;-14 ;-3$ & 233 & 3.65 & Right superior temporal gyrus \\
& $-2 ; 53 ;-14$ & 309 & 3.60 & Left orbitofrontal gyrus \\
& $6 ;-24 ; 42$ & 80 & 3.45 & Right dorsal posterior cingulate \\
\hline
\end{tabular}

FCSRT, Free and Cued Selective Reminding.

evaluation may have had a better possibility of correlating with anosognosia. To assess an alteration of this comparator process, the Judgement of Learning paradigm (JOL) would be more suitable for properly assessing this hypothesis [53].

Thus, we can propose that atrophy and hypometabolism in the dACC may explain, to a certain extent, the awareness deficit in AD patients. An alteration of this region, apparently involved in executive processes, can explain the hypothesis of a lack of personal database updating in anosognosic patients. The monitoring process could be deficient, leading to an alteration of the comparator mechanism. A disconnection between the cingulate cortex and the temporal lobe could also explain the alteration of information transfer between online monitoring and self-representation [22]. A recent study of three different memory training programs using a global JOL paradigm in $51 \mathrm{AD}$ patients showed alteration of the information online transfer to the personal database, rather than a lack of updating or an alteration of the comparator mechanism [54].

In addition to being involved in executive processes, the anterior cingulate also plays an important role in apathy process [55, 56]. In 2007, Apostolova and colleagues [55] reported a negative correlation between the apathy severity and the grey matter density in $17 \mathrm{AD}$ patients. Some studies have also reported positive correlations between apathy and anosognosia in AD (see [11] for review). Rosen in 2011 [57] suggested that motivational and emotional factors could play an important role in self-monitoring engagement and error detection and therefore would modulate the awareness level. Another important imaging result in this study is the correlation between grey matter density in the posterior cerebellar vermis found in $\mathrm{AD}$ patients and the anosognosia score. However, no alteration of metabolism related to anosognosia was found in this region. Executive functions are principally supported by the posterior cerebellum, and more precisely the lobules VI/Crus I and VIIB [58]. However, the altered region found in our study is the posterior vermis of the cerebellum, which is primarily involved in emotional processes $[59,60]$. In a recent study, Bertrand et al. [60] reported that induction of a negative mood state after a failed memory task induced an augmentation of the awareness level. We can also postulate that during task performance, the presence of apathy or an altered emotional process in these patients can alter the detection of a difference between the actual self-information collected (e.g., the failure of the task) and the old information about oneself, leading to a lack of selection of this new information. The perceived difference may also be minimized or ignored [61].

In addition, we didn't find any correlation between apathy and dACC structure or metabolism. However, correlations between apathy and metabolism were found in the associative visual cortex (BA19). These results are in agreement with previous studies in healthy subjects [62] and MCI patients [63]. In our study, the distribution of the apathy score limits the interpretation of the results.

Other results were the grey matter density of the right fusiform gyrus and the left postcentral gyrus, which was negatively correlated with the anosognosia score. A diminution of connectivity between the fusiform gyrus and hippocampi in connection with anosognosia in MCI was reported in a recent study but not discussed [64]. Concerning the left postcentral gyrus, its involvement is better known in self-referential processing in the spatial domain than self-referential processing in the memory domain. 
Currently, no strong explanation was found for the involvement of these structures.

As mentioned above, more specific testing of highlevel executive function (response selection, error detection, performance monitoring, reappraisal, and judgement of self-related stimuli) would be of great interest in future studies. Similarly, a specific ecological memory task would have a better chance of responding to the memory hypothesis for anosognosia. In fact, it is highly probable that "real life" autobiographical data related to the self and episodic memory are not integrated in the same way [65]. Concerning the anosognosia score, it is worth noting that the mean of anosognosia in healthy controls is negative but similar results had previously found in literature $[22,66]$. As mentioned, we found in the $\mathrm{AD}$ group a wide distribution of the anosognosia score along a continuum. The choice of a cut-off for the anosognosia score was impossible (see Supplementary Figure 3). Therefore, we chose to use correlations. The inclusion of more patients in this study might have allowed us to find a bimodal distribution for this anosognosia score and therefore create two distinct groups.

\section{Conclusion}

This study combines a neuropsychological, structural, and metabolic assessment of anosognosia in AD patients. We found that the ACC seems to play a significant role in anosognosia. This region seems important for executive functions and specifically data updating, essential in awareness processes. One way to further explore this hypothesis would be to design a specific executive function assessment to evaluate the inner cognitive mechanisms of selection, error detection, performance monitoring, reappraisal, and judgement of self-related stimuli.

\section{ACKNOWLEDGMENTS}

The authors thank the patients and control participants who took part in this study, as well as the promoter of this study, Toulouse University Hospital (CHU). Our gratitude goes to Dr. Sophie Dechaumont-Palacin, Dr. Michèle Puel, Thomas Busigny, Laure Saint-Aubert, and Aurélie Pistono for their involvement and help in this project. This research did not receive any specific grant from funding agencies in the public, commercial, or notfor-profit sectors.
Authors' disclosures available online (https:// www.j-alz.com/manuscript-disclosures/18-0324r3).

\section{SUPPLEMENTARY MATERIAL}

The supplementary material is available in the electronic version of this article: http://dx.doi.org/ 10.3233/JAD-180324.

\section{REFERENCES}

[1] Aalten P, van Valen E, de Vugt ME, Lousberg R, Jolles J, Verhey FR (2006) Awareness and behavioral problems in dementia patients: A prospective study. Int Psychogeriatr 18, 3-17.

[2] Mograbi DC, Ferri CP, Sosa AL, Stewart R, Laks J, Brown R, Morris RG (2012) Unawareness of memory impairment in dementia: A population-based study. Int Psychogeriatr 24, 931-939.

[3] Lehrer DS, Lorenz J (2014) Anosognosia in schizophrenia: Hidden in plain sight. Innov Clin Neurosci 11, 10-17.

[4] Nurmi Laihosalo ME, Jehkonen M (2014) Assessing anosognosias after stroke: A review of the methods used and developed over the past 35 years. Cortex 61, 43-63.

[5] Piras F, Piras F, Orfei MD, Caltagirone C, Spalletta G (2016) Self-awareness in Mild Cognitive Impairment: Quantitative evidence from systematic review and meta-analysis. $\mathrm{Neu}$ rosci Biobehav Rev 61, 90-107.

[6] Vogel A, Stokholm J, Gade A, Andersen BB, Hejl AM, Waldemar G (2004) Awareness of deficits in mild cognitive impairment and Alzheimer's disease: Do MCI patients have impaired insight? Dement Geriatr Cogn Disord 17, 181187.

[7] Vogel A, Hasselbalch SG, Gade A, Ziebell M, Waldemar $\mathrm{G}$ (2005) Cognitive and functional neuroimaging correlates for anosognosia in mild cognitive impairment and Alzheimer's disease. Int J Geriatr Psychiatry 20, 238-246.

[8] Kashiwa Y, Kitabayashi Y, Narumoto J, Nakamura K, Ueda H, Fukui K (2005) Anosognosia in Alzheimer's disease: Association with patient characteristics, psychiatric symptoms and cognitive deficits. Psychiatry Clin Neurosci 59, 697-704.

[9] Antoine C, Antoine P, Guermonprez P, Frigard B (2004) Conscience des déficits et anosognosie dans la maladie d'Alzheimer. Encephale 30, 570-577.

[10] Kotler-Cope S, Camp CJ (1995) Anosognosia in Alzheimer disease. Alzheimer Dis Assoc Disord 9, 52-56.

[11] Starkstein SE (2014) Anosognosia in Alzheimer's disease: Diagnosis, frequency, mechanism and clinical correlates. Cortex 61, 64-73.

[12] Nelson TO, Narens L (1990) Metamemory: A theoretical framework and new findings. Psychol Learn Motiv 26, 125173.

[13] Agnew SK, Morris RG (1998) The heterogeneity of anosognosia for memory impairment in Alzheimer's disease: A review of the literature and a proposed model. Aging Ment Health 2, 7-19.

[14] Lopez OL, Becker JT, Somsak D, Dew MA, DeKosky ST (1994) Awareness of cognitive deficits and anosognosia in probable Alzheimer's disease. Eur Neurol 34, 277-282.

[15] Amanzio M, Vase L, Leotta D, Miceli R, Palermo S, Geminiani G (2012) Impaired awareness of deficits in Alzheimer's 
disease: The role of everyday executive dysfunction. $J$ Int Neuropsychol Soc 19, 69-72.

[16] Migliorelli R, Tesón A, Sabe L, Petracca G, Petracchi M, Leiguarda R, Starkstein SE (1995) Anosognosia in Alzheimer's disease: A study of associated factors. $J \mathrm{Neu}$ ropsychiatry Clin Neurosci 7, 338-344.

[17] Morris RG, Mograbi DC (2013) Anosognosia, autobiographical memory and self knowledge in Alzheimer's disease. Cortex 49, 1553-1565.

[18] Spalletta G, Girardi P, Caltagirone C, Orfei MD (2012) Anosognosia and neuropsychiatric symptoms and disorders in mild Alzheimer disease and mild cognitive impairment. J Alzheimers Dis 29, 761-772.

[19] Rosen HJ, Alcantar O, Rothlind J, Sturm V, Kramer JH, Weiner M, Miller BL (2010) Neuroanatomical correlates of cognitive self-appraisal in neurodegenerative disease. $\mathrm{Neu}$ roimage 49, 3358-3364.

[20] Fujimoto H, Matsuoka T, Kato Y, Shibata K, Nakamura K, Yamada K, Narumoto J (2017) Brain regions associated with anosognosia for memory disturbance in Alzheimer's disease: A magnetic resonance imaging study. Neuropsychiatr Dis Treat 13, 1753-1759.

[21] Spalletta G, Piras F, Piras F, Sancesario G, Iorio M, Fratangeli C, Cacciari C, Caltagirone C, Orfei MD (2014) Neuroanatomical correlates of awareness of illness in patients with amnestic mild cognitive impairment who will or will not convert to Alzheimer's disease. Cortex 61, 183195.

[22] Perrotin A, Desgranges B, Landeau B, Mézenge F, La Joie R, Egret S, Pélerin A, de la Sayette V, Eustache F, Chételat G (2015) Anosognosia in Alzheimer disease: Disconnection between memory and self-related brain networks. Ann Neurol 78, 477-486.

[23] Hanyu H, Sato T, Akai T, Shimizu S, Hirao K, Kanetaka H, Iwamoto T, Koizumi K (2008) Neuroanatomical correlates of unawareness of memory deficits in early Alzheimer's disease. Dement Geriatr Cogn Disord 25, 347-353.

[24] Salmon E, Perani D, Herholz K, Marique P, Kalbe E, Holthoff V, Delbeuck X, Beuthien-Baumann B, Pelati O, Lespagnard S, Collette F, Garraux G (2006) Neural correlates of anosognosia for cognitive impairment in Alzheimer's disease. Hum Brain Mapp 27, 588-597.

[25] Dubois B, Feldman HH, Jacova C, Hampel H, Molinuevo JL, Blennow K, DeKosky ST, Gauthier S, Selkoe D, Bateman R, Cappa S, Crutch S, Engelborghs S, Frisoni GB, Fox NC, Galasko D, Habert MO, Jicha GA, Nordberg A, Pasquier F, Rabinovici G, Robert P, Rowe C, Salloway S, Sarazin M, Epelbaum S, de Souza LC, Vellas B, Visser PJ, Schneider L, Stern Y, Scheltens P, Cummings JL (2014) Advancing research diagnostic criteria for Alzheimer's disease: The IWG-2 criteria. Lancet Neurol 13, 614-629.

[26] Alexopoulos GS, Abrams RC, Young RC, Shamoian CA (1988) Cornell scale for depression in dementia. Biol Psychiatry 23, 271-284.

[27] Van der Linden M, Coyette F, Poitrenaud J, Kalafat M, Calicis F, Wyns C, Adam S (2004) 16-item free recall/cued recall test (RL/RI-16). In L'évaluation des troubles de la mémoiré: Présentation de quatre tests de mémoire épisodique (avec leur étalonnage), Solal, ed., pp. 25-47.

[28] Wallon D, Rousseau S, Rovelet-Lecrux A, QuillardMuraine M, Guyant-Maréchal L, Martinaud O, Pariente J, Puel M, Rollin-Sillaire A, Pasquier F, Le Ber I, Sarazin M, Croisile B, Boutoleau-Bretonnière C, ThomasAntérion C, Paquet C, Moreaud O, Gabelle A, Sellal F, Sauvée M, Laquerrière A, Duyckaerts C, Delisle MB,
Streichenberger N, Lannes B, Frebourg T, Hannequin D, Campion D; collaborators of GMAJ project (2012) The French series of autosomal dominant early onset Alzheimer's disease cases: Mutation spectrum and cerebrospinal fluid biomarkers. J Alzheimers Dis 30, 847-856.

[29] Israël L (1986) Échelle d'auto-évaluation des difficultés de la vie quotidienne (Cognitive Difficulties Scale) C.D.S. In L'évaluation clinique standardisée en psychiatrie, Guefli J-D, ed. Pierre Fabre, Paris, pp. 485-491.

[30] McNair D, Kahn R (1983) Self-assessment of cognitive deficits scale. In Assessment in Geriatric Psychopharmacology, Crook T, Ferris S, Bartus R, eds. Mark Powley and Associates, New Canaan, CT, pp. 137-143.

[31] Cockburn JM (1996) Behavioural assessment of memory in normal old age. Eur Psychiatry 11, 205s.

[32] Godefroy O (2008) le GREFEX. In Fonctions exécutives et pathologies neurologiques et psychiatriques, Solal, ed., Marseille.

[33] Wechsler D (1997) Wechsler Adult Intelligence Scale Administration and Scoring Manual. Psychological Corp, San Antonio, TX.

[34] Bachy-Langedock N (1989) Batterie d'examen des troubles de la dénomination (ExaDé), Editest, Bruxelles.

[35] Mahieux-Laurent F, Fabre C, Galbrun E, Dubrulle A, Moroni C; groupe de réflexion sur les praxies du CMRR Ile-de-France Sud (2009) Validation of a brief screening scale evaluating praxic abilities for use in memory clinics. Evaluation in 419 controls, 127 mild cognitive impairment and 320 demented patients. Rev Neurol (Paris) 165, 560-567.

[36] Robert ph, Clairet S, Benoit M, Koutaich J, Bertogliati C, Tible O, Caci H, Borg M, Brocker P, Bedoucha P (2002) The Apathy Inventory: Assessment of apathy and awareness in Alzheimer's disease, Parkinson's disease and mild cognitive impairment. Int J Geriatr Psychiatry 17, 1099-1105.

[37] Katz S, Downs TD, Cash HR, Grotz RC (1970) Progress in development of the index of ADL. Gerontologist 10, 20-30.

[38] Lawton MP, Brody EM (1969) Assessment of older people: Self-maintaining and instrumental activities of daily living. Gerontologist 9, 179-186.

[39] Brett MC, Anton JL, Valabregue R, Poline JB (2002) Region of interest analysis using the MarsBar toolbox for SPM 99. Neuroimage 16, S497.

[40] Hannesdottir K, Morris RG (2007) Primary and secondary anosognosia for memory impairment in patients with Alzheimer's disease. Cortex 43, 1020-1030.

[41] Chételat G, Desgranges B, Landeau B, Mézenge F, Poline JB, de la Sayette V, Viader F, Eustache F, Baron JC (2008) Direct voxel-based comparison between grey matter hypometabolism and atrophy in Alzheimer's disease. Brain 131, 60-71.

[42] McCormick LM, Ziebell S, Nopoulos P, Cassell M, Andreasen NC, Brumm M (2006) Anterior cingulate cortex: An MRI-based parcellation method. Neuroimage 32, 1167-1175.

[43] Northoff G, Heinzel A, de Greck M, Bermpohl F, Dobrowolny H, Panksepp J (2006) Self-referential processing in our brain-A meta-analysis of imaging studies on the self. Neuroimage 31, 440-457.

[44] Vogt BA (2016) Midcingulate cortex: Structure, connections, homologies, functions and diseases. $J$ Chem Neuroanat 74, 28-46.

[45] Northoff G, Bermpohl F (2004) Cortical midline structures and the self. Trends Cogn Sci 8, 102-107. 
[46] Carter CS, Braver TS, Barch DM, Botvinick MM, Noll D, Cohen JD (1998) Anterior cingulate cortex, error detection, and the online monitoring of performance. Science 280, 747749.

[47] Wong S, Irish M, Leshikar ED, Duarte A, Bertoux M, Savage G, Hodges JR, Piguet O, Hornberger M (2017) The self-reference effect in dementia: Differential involvement of cortical midline structures in Alzheimer's disease and behavioural-variant frontotemporal dementia. Cortex 91, 169-185.

[48] Amanzio M, Torta DM, Sacco K, Cauda F, D' Agata F, Duca S, Leotta D, Palermo S, Geminiani GC (2011) Unawareness of deficits in Alzheimer's disease: Role of the cingulate cortex. Brain 134, 1061-1076.

[49] Mograbi DC, Brown RG, Morris RG (2009) Anosognosia in Alzheimer's disease - the petrified self. Conscious Cogn 18, 989-1003.

[50] Conway MA (2005) Memory and the self. J Mem Lang 53, 594-628.

[51] Duval C, Eustache F, Piolino P (2007) Self multidimensionnel, mémoire autobiographique et vieillissement. Psychol Neuropsychiatr du Vieil 5, 179-192.

[52] Ansell EL, Bucks RS (2006) Mnemonic anosognosia in Alzheimer's disease: A test of Agnew and Morris (1998). Neuropsychologia 44, 1095-1102.

[53] Souchay C (2007) Metamemory in Alzheimer's disease. Cortex 43, 987-1003.

[54] Silva AR, Pinho MS, Macedo L, Souchay C, Moulin C (2017) Mnemonic anosognosia in Alzheimer's disease is caused by a failure to transfer online evaluations of performance: Evidence from memory training programs. J Clin Exp Neuropsychol 39, 419-433.

[55] Apostolova LG, Akopyan GG, Partiali N, Steiner CA, Dutton RA, Hayashi KM, Dinov ID, Toga AW, Cummings JL, Thompson PM (2007) Structural correlates of apathy in Alzheimer's disease. Dement Geriatr Cogn Disord 24, 91-97.

[56] Marshall GA, Fairbanks LA, Tekin S, Vinters HV, Cummings JL (2006) Neuropathologic correlates of apathy in
Alzheimer's disease. Dement Geriatr Cogn Disord 21, 144147.

[57] Rosen HJ (2011) Anosognosia in neurodegenerative disease. Neurocase 17, 231-241.

[58] Stoodley CJ, Schmahmann JD (2010) Evidence for topographic organization in the cerebellum of motor control versus cognitive and affective processing. Cortex 46, 831844.

[59] Schmahmann JD, Weilburg JB, Sherman JC (2007) The neuropsychiatry of the cerebellum - insights from the clinic. Cerebellum 6, 254-267.

[60] Bertrand E, Dourado MC, Laks J, Morris RG, LandeiraFernandez J, Mograbi DC (2016) Mood-congruent recollection and anosognosia in Alzheimer's disease. Cortex 84, 55-62.

[61] Mograbi DC, Morris RG (2014) On the relation among mood, apathy, and anosognosia in Alzheimer's disease. J Int Neuropsychol Soc 20, 2-7.

[62] Spalletta G, Fagioli S, Caltagirone C, Piras F (2013) Brain microstructure of subclinical apathy phenomenology in healthy individuals. Hum Brain Mapp 34, 3193-3203.

[63] Kazui H, Takahashi R, Yamamoto Y, Yoshiyama K, Kanemoto H, Suzuki Y, Sato S, Azuma S, Suehiro T, Shimosegawa E, Ishii K, Tanaka T (2017) Neural basis of apathy in patients with amnestic mild cognitive impairment. J Alzheimers Dis 55, 1403-1416.

[64] Vannini P, Hanseeuw B, Munro CE, Amariglio RE, Marshall GA, Rentz DM, Pascual-Leone A, Johnson KA, Sperling RA (2017) Anosognosia for memory deficits in mild cognitive impairment: Insight into the neural mechanism using functional and molecular imaging. Neuroimage Clin 15, 408-414.

[65] Klein SB, Cosmides L, Costabile KA (2003) Preserved knowledge of self in a case of Alzheimer's dementia. Soc Cogn 21, 157-165.

[66] Stewart G, McGeown WJ, Shanks MF, Venneri A (2010) Anosognosia for memory impairment in Alzheimer's disease. Acta Neuropsychiatr 22, 180-187. 